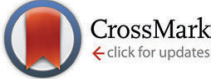

Cite this: Chem. Commun., 2016, 52,6565

Received 24th February 2016, Accepted 15th April 2016

DOI: $10.1039 / c 6 c c 01689 h$

www.rsc.org/chemcomm

\section{A switchable dual organocatalytic system and the enantioselective total synthesis of the quadrane sesquiterpene suberosanone $\dagger$}

\author{
Yajun Ren, ${ }^{a}$ Marc Presset,$\ddagger^{a}$ Jeremy Godemert, ${ }^{a}$ Nicolas Vanthuyne, ${ }^{a}$ \\ Jean-Valère Naubron, ${ }^{b}$ Michel Giorgi, ${ }^{b}$ Jean Rodriguez ${ }^{\star a}$ and Yoann Coquerel ${ }^{\star a}$
}

The combination of aminocatalysis with $\mathrm{N}$-heterocyclic carbene catalysis has been extended to a switchable dual catalytic system, which allowed a direct enantioselective entry to bridged bicyclo[3.n.1] ring systems and the total synthesis of the natural product $(1 R)$-suberosanone.

Quadranes form a small class of cytotoxic sesquiterpene natural products, originated either from terrestrial or marine organisms, and belonging to the larger group of polyquinanes. ${ }^{1}$ It is worth mentioning that natural products have in the past and continue to play a crucial role in the discovery of drugs for the benefit of mankind. ${ }^{2}$ Although the first known naturally occurring quadrane, namely quadrone, was isolated back in 1978 , despite considerable synthetic efforts, no enantioselective total synthesis of a quadrane natural product has been reported. ${ }^{1,3}$ Actually, most quadranes are of unknown absolute configuration even though they are all presumed to exist naturally as their $(1 R)$ enantiomers. ${ }^{1,4}$ The absolute configuration of the quadrane suberosanone (1) was recently assigned as $(1 S)$ by chemical synthesis. ${ }^{5}$ Intrigued by this oddity, and motivated by the development of an original enantioselective organocatalytic method for the synthesis of functionalized bridged bicyclo[3.2.1] octane compounds ${ }^{6}$ applicable to the synthesis of most, if not all, quadranes, we embarked on the total synthesis of $(1 R)$-suberosanone (1). It was devised that $(1 R)-\mathbf{1}$ would be accessible in a few steps starting from the bicyclo[3.2.1]octane $(1 R)-2$, which we planned to prepare using a yet-to-discover enantioselective dual organocatalytic Michael/aldolization sequence from the $\beta$-ketoester 4 and crotonaldehyde (5a, Scheme 1).

\footnotetext{
${ }^{a}$ Aix Marseille Université, Centrale Marseille, CNRS, iSm2 UMR7313,

F-13397 Marseille, France.E-mail: jean.rodriguez@univ-amu.fr, yoann.coquerel@univ-amu.fr; Fax: +33 491289 187; Tel: +33 491289088

${ }^{b}$ Aix Marseille Université, CNRS, Spectropole FR1739, F-13397 Marseille, France

$\dagger$ Electronic supplementary information (ESI) available: Procedures, characterization data and copies of NMR spectra and HPLC chromatograms for all compounds; CIF for compound 8a. CCDC 1449766. For ESI and crystallographic data in CIF or other electronic format see DOI: $10.1039 / \mathrm{c} 6 \mathrm{cc} 01689 \mathrm{~h}$

\$ Present address: Université Paris-Est, ICMPE (UMR 7182), CNRS, UPEC, F-94320 Thiais, France.
}

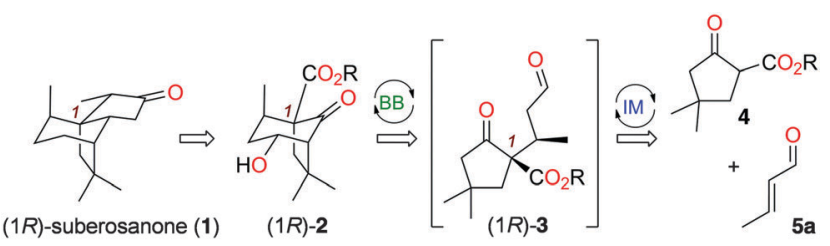

Scheme 1 Retrosynthetic analysis for suberosanone, and planned enantioselective dual organocatalytic Michael/aldol sequence. $\mathrm{BB}=$ Brønsted base activation. $I M=$ iminium activation.

Based on the accumulated knowledge on enantioselective organocatalytic Michael additions with 1,3-dicarbonyl compounds, we were confident that highly enantio-enriched Michael adduct intermediates of type 3 could be obtained from pronucleophiles of type 4 under iminium activation. ${ }^{8}$ An additional Brønsted base would then be required to operate the ring-closing aldolization step. Although enticing, this idea raised some challenging issues: (i) iminium activation is a reversible process; ${ }^{8}$ (ii) previous work on the synthesis of bridged ring systems of type 2 via Brønsted basepromoted Michael/aldolization sequences in the racemic series established that these reactions are fully reversible when performed with common Brønsted bases (e.g. DBU); ${ }^{9}$ (iii) Michael adducts of type 3 readily racemize, precluding their isolation in high enantiopurity under standard conditions; ${ }^{10 a}$ and (iv) intermediates of type $\mathbf{3}$ amenable to applications to the total synthesis of quadranes exhibit a gem-dimethyl group in the vicinity of the aldolization site, which should both notably slow down the aldolization step and favor Brønsted base-catalyzed retroMichael/Michael processes leading to racemization. Recently, it was discovered that hindered imidazolylidene N-heterocyclic carbenes (NHCs) are potent Brønsted bases capable of catalyzing Michael/aldolization sequences, but with little tendency for reversibility. ${ }^{11}$ It was hypothesized that the planned enantioselective Michael/aldolization sequence leading to $(1 R)-2$ could be achieved using a sequential combination of the aminocatalyst I and the NHC catalyst II in a one-pot dual catalytic process. ${ }^{12}$

In order to test this idea, the prototypical reactions of the $\beta$-ketoesters $4 \mathbf{a}$ and $\mathbf{4 d}$ with crotonaldehyde (5a) were examined 
under various dual catalytic conditions (Table 1). Because all the four possible diastereomers of $\mathbf{2 a , d}$ can be expected in different proportions, the crude reaction products were directly oxidized into the corresponding diketones $\mathbf{6 a , d}$ to simplify analysis. The benchmark result was obtained by the sequential combination of catalyst I and DBU, which afforded product $\mathbf{6 a}$ with low enantioselectivity due to DBU-catalyzed racemization processes (entry 1). In contrast, it was found that the sequential addition of catalysts I and II to solutions of $\mathbf{4 a}$ and $5 \mathbf{a}$ produced, after oxidation, the diketone $\mathbf{6 a}$ in generally good yields and stereoselectivities (entries 2-5). The reaction in dichloromethane (entry 2) gave the best enantioselectivity but a low yield, which could be improved in toluene (entry 3). Alternatively, methanol afforded comparable results in a somewhat accelerated reaction (entry 4), while substituting catalyst I by the so-called MacMillan's second generation catalyst ${ }^{13}$ gave $6 \mathbf{6}$ in lower yield and enantioselectivity (entry 5). Other dual organocatalytic systems combining an aminocatalyst with a NHC have been reported in the past few years. ${ }^{14}$ Among these, Lathrop and Rovis reported an elegant enantioselective Michael/crossed benzoin sequence from the methyl ester analog of $\mathbf{4 a}$ (the precursor of $\mathbf{6 c}$, see Fig. 1) and aldehyde 5a using a combination of catalyst $\mathbf{I}$ and an achiral triazolylidene NHC catalyst to give a fused bicyclo[3.3.0]octane product. ${ }^{10,15}$ Remarkably, and in sharp contrast to the Lathrop and Rovis study, no fused bicyclo[3.3.0]octane products could be detected in the intermediate crude products 2 , illustrating the perfectly switchable nature of the overall dual organocatalytic transformation as a function of the NHC catalyst employed (triazolylidene $v s$. hindered imidazolylidene). ${ }^{16}$ More generally, this represents the first described switchable dual catalytic enantioselective transformation. Stimulated by these results, we then moved to the more

Table 1 Optimization of the dual catalytic reaction (selected results)

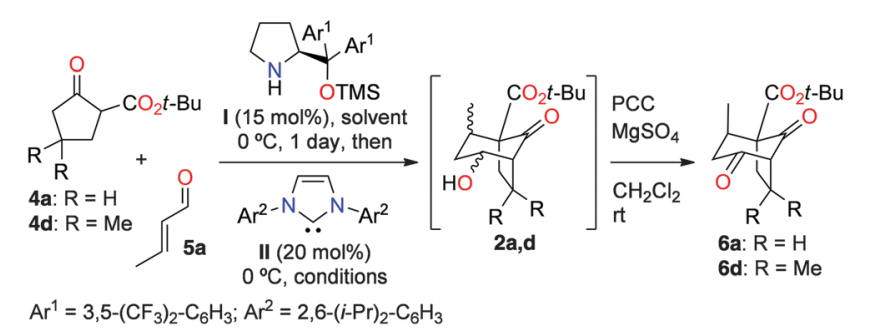

\begin{tabular}{llllll}
\hline Entry & Solvent & Conditions & Yield $^{a}$ & $\mathrm{dr}^{b}$ & $\mathrm{er}^{c}$ \\
\hline $1^{d}$ & $\mathrm{MeOH}$ & 2 days & $\mathbf{6 a}, 77 \%$ & $3: 1$ & $5: 1$ \\
2 & $\mathrm{CH}_{2} \mathrm{Cl}_{2}$ & 2 days & $\mathbf{6 a}, 28 \%$ & $4: 1$ & $27: 1$ \\
3 & Toluene & 2 days & $\mathbf{6 a}, 71 \%$ & $4: 1$ & $26: 1$ \\
4 & $\mathrm{MeOH}$ & 1 day & $\mathbf{6 a}, 75 \%$ & $4: 1$ & $18: 1$ \\
$5^{e}$ & $\mathrm{MeOH}$ & 1 day & $\mathbf{6 a}, 60 \%$ & $4: 1$ & $10: 1$ \\
6 & Toluene & 2 days & $\mathbf{6 d},<5 \%$ & - & - \\
7 & $\mathrm{MeOH}$ & 1 day & $\mathbf{6 d}, 80 \%$ & $2: 1$ & $8: 1$ \\
$8^{f}$ & $\mathrm{MeOH}$ & 3 days & $\mathbf{6 d}, 90 \%$ & $2: 1$ & $12: 1$ \\
9 & $\mathrm{MeOH}$ & AcOH $(20 \mathrm{~mol} \%), 4$ days & $\mathbf{6 d}, 90 \%$ & $2: 1$ & $16: 1$
\end{tabular}

${ }^{a}$ For the isolated pure product ( $0.5 \mathrm{mmol}$ scale reactions). ${ }^{b}$ Determined by NMR analysis of the crude product. ${ }^{c}$ For the major diastereomer, determined by HPLC. ${ }^{d}$ Reaction performed with DBU instead of II. ${ }^{e}$ Reaction performed with so-called MacMillan's second generation catalyst instead of I. ${ }^{f}$ Reaction performed with only $3 \mathrm{~mol} \%$ of II.

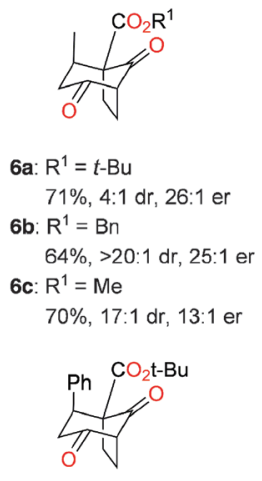

6j: $28 \%, 2: 1 d r, 11: 1 \mathrm{er}$

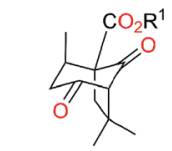

6d: $\mathrm{R}^{1}=t-\mathrm{Bu}$

$90 \%, 2: 1 \mathrm{dr}, 16: 1 \mathrm{er}$

6e: $\mathrm{R}^{1}=\mathrm{Bn}$

$60 \%, 2: 1 \mathrm{dr}, 9: 1$ er

6f: $\mathrm{R}^{1}=\mathrm{Me}$

$60 \%, 2: 1 \mathrm{dr}, 13: 1 \mathrm{er}$

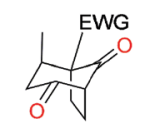

6k: $E W G=\mathrm{COMe}$

$54 \%, 8: 1 \mathrm{dr}, 16: 1$ e

6l: $\mathrm{EWG}=\mathrm{SO}_{2} \mathrm{Ph}$

$66 \%, 2: 1 \mathrm{dr}, 11: 1 \mathrm{er}$

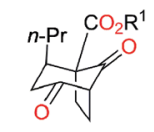

6g: $\mathrm{R}^{1}=t-\mathrm{Bu}$

6h: $\mathbf{R}^{1}=\mathrm{Bn}$

$48 \%, 15: 1 \mathrm{dr},>9: 1 \mathrm{er}$

6i: $\mathrm{R}^{1}=\mathrm{Me}$

$50 \%,>20: 1 \mathrm{dr}, 42: 1$ er

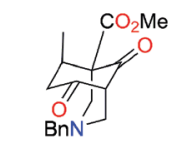

6m: $56 \%, 2: 1 \mathrm{dr}, 6: 1 \mathrm{er}$
$61 \%, 4: 1 \mathrm{dr}, 16: 1 \mathrm{er}$

Fig. 1 Scope of the dual organocatalytic reaction. See the ESI $\dagger$ for full experimental details.

challenging substrate $4 \mathbf{d}$ (entries 6-9). In that case, the reaction was only found possible in methanol and afforded product $\mathbf{6 d}$ with moderate enantioselectivity under the conditions previously used for 6a (compare entries 4 and 7). It was hypothesized that reducing the amount of free NHC II in solution would limit the undesired competitive NHC-catalyzed Michael addition leading to racemization. Indeed, a reaction conducted with only $3 \mathrm{~mol} \%$ of II allowed the isolation of product $\mathbf{6 d}$ with a significantly better enantioselectivity (entry 8). Following the same idea, masking the NHC as its azolium salt in situ should allow maintaining of only a tiny amount of the free NHC II in solution. In practice, it was found that adding acetic acid together with II after the Michael addition step afforded the product $\mathbf{6 d}$ in good yield and improved enantioselectivity, at the expense of prolonged reaction time (entry 9). ${ }^{17}$ The reaction was then examined using other cyclic $\alpha$-activated ketones and $\alpha, \beta$-unsaturated aldehydes, which afforded the bridged bicyclic products $\mathbf{6 a - m}$ with good to excellent yields and stereoselectivities (Fig. 1). The enhancement of diastereoselectivity observed in many cases was expected and ensued from the decomposition of the minor diastereomers of 2 having equatorial substituents by methanolmediated retro-Dieckmann fragmentation processes (see the $\mathrm{ESI} \dagger)^{9}{ }^{9,18}$ In a few cases, the MacMillan's second generation catalyst ${ }^{13}$ performed better than its counterpart I (e.g. for $\mathbf{6 i}$ and $\mathbf{6 j}$, see the ESI $\dagger$ ). The determination of the absolute configurations in products $\mathbf{6 a - m}$ is based on previous work, ${ }^{8,10}$ and was confirmed by derivatization, X-ray diffraction analysis, and full chiroptical characterization of the targeted natural product (see below and the ESI $\dagger$ ).

With the new enantioselective methodological tool described above in hand, the total synthesis started with a scale up study, which afforded $2 \mathrm{~d}$ as a mixture of four diastereomers in $90 \%$ yield on a 12 gram scale (Scheme 2). The oxidation of an analytic sample of $2 \mathbf{d}$ delivered the diketone $\mathbf{6 d}$ with similar yield and stereoselectivities when compared to the methodological scale series $(2: 1 \mathrm{dr}, 8: 1 \mathrm{er}$, compare with Table 1 , entry 7$) .{ }^{19}$ The Barton-McCombie deoxygenation of $\mathbf{2 d}$ afforded the key intermediate 7 in $85 \%$ yield ( $2: 1 \mathrm{dr}, 9.2 \mathrm{~g}$ batch), which was later in 

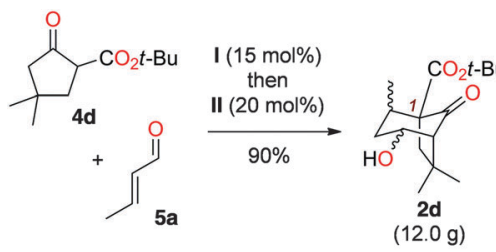

1) $\mathrm{NaH}, \mathrm{CS}_{2}$

then Mel

2) $n-\mathrm{Bu}_{3} \mathrm{SnH}$

$\underset{85 \%, 2 \text { steps }}{\stackrel{\text { AIBN }}{\longrightarrow}}$

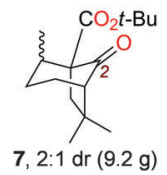

7, 2:1 dr (9.2 g)

$\mathrm{NaBH}_{4} \downarrow 77 \%$

$\mathrm{CO}_{2} t-\mathrm{Bu}$

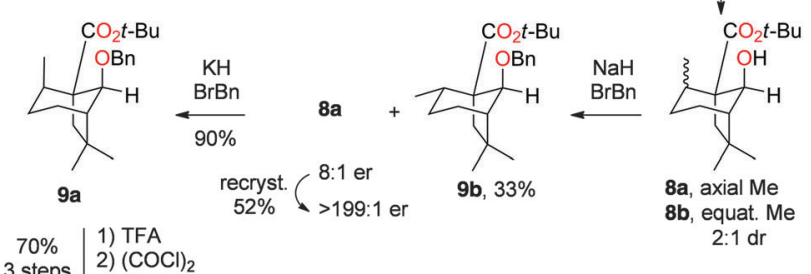

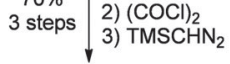

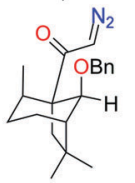

10
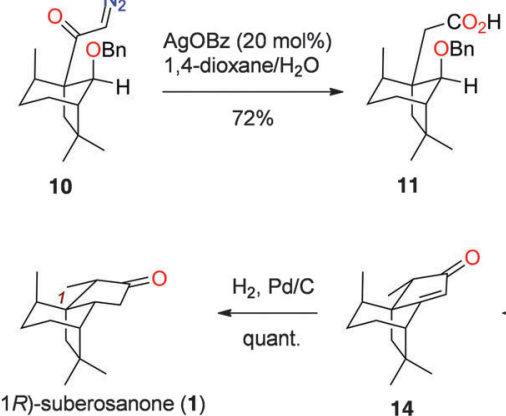

14
11

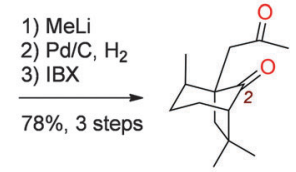

12

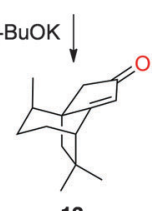

13
Scheme 2 Total synthesis of (1R)-suberosanone (1)

the synthesis confirmed to maintain the $8: 1$ er of the major diastereomer. The initially planned strategy to convert 7 into the natural product 1 and its congeners was relied on the early olefination of the ketone carbonyl group at C2. Regrettably, we soon had to face the problem that the $\mathrm{C} 2$ carbonyl group and the corresponding olefins were extremely difficult to react, and when possible, with the desired diastereoselectivity. These difficulties were attributed to severe cumulative steric effects at $\mathrm{C} 2$ caused by its neopentylic position, a 1,3-diaxial interaction on the $\beta$-face, a gem-dimethyl group on the $\alpha$-face, and a conformational rigidity. Overall, the chemical transformation of the key intermediate 7 revealed to be much more difficult than anticipated, but also more exciting. Ultimately, we had to proceed through the protection of the ketone group at $\mathrm{C} 2$ in two steps for the reasons given above, which actually turned out beneficial for the issue of the total synthesis. The diastereoselective reduction of the ketone group in 7 ( $2: 1 \mathrm{dr})$ with sodium borohydride afforded the corresponding mixture of diastereomers $8 \mathbf{a}$ and $\mathbf{8 b}(77 \%$, $2: 1 \mathrm{dr}$ ). Following the serendipitous observation that $8 \mathbf{a}$ and $\mathbf{8 b}$ could be kinetically differentiated in etherification reactions, they were separated by the selective benzylation of the minor diastereomer $\mathbf{8 b}$ having an equatorial methyl group to give $\mathbf{9 b}$ using $\mathrm{NaH} / \mathrm{BrBn}$. A single recrystallization of the remaining diastereomerically pure alcohol 8a (>50:1 dr, 8:1 er) afforded enantiopure crystalline 8a $(52 \%,>199: 1 \mathrm{er})$ suitable for X-ray diffraction analysis, which confirmed both its relative and absolute configurations to be as depicted (see the ESI $\dagger$ ). ${ }^{20}$ The alcohol 8a was then converted into its benzyl ether 9a using $\mathrm{KH} / \mathrm{BrBn}$, and the subsequent Arndt-Eistert homologation ${ }^{21}$ afforded the carboxylic acid $\mathbf{1 1}$ via the methyldiazoketone 10. The carboxylic moiety in $\mathbf{1 1}$ was transformed into the corresponding methyl ketone with methyl lithium, and the $\mathrm{C} 2$ carbonyl group was restored to afford the desired diketone 12. From 12, the endgame strategy was largely inspired by previous work on the total syntheses of quadranes. ${ }^{1}$ It was found that $t$-BuOK promoted an efficient ring-closing aldolization/dehydration sequence from 12 to give the corresponding cyclopentenone 13, the diastereoselective $\alpha$-methylation of which under standard conditions furnished the tricyclic late intermediate 14. Finally, the diastereoselective hydrogenation of the double bond in $\mathbf{1 4}$ afforded quantitatively the target product $(1 R)$-suberosanone (1). The enantioselective synthesis of $\mathbf{1 2}$ also constitutes a formal enantioselective total synthesis of the related quadrane natural product $(1 R)$-suberosenone. ${ }^{5}$

With synthetic samples of $(1 R)-\mathbf{1}$ in hand, we tackled the issue of the determination of the absolute configuration of naturally occurring $\mathbf{1}$. To do so, we performed a full chiroptical characterization of $(1 R)-\mathbf{1}$, including optical rotatory dispersion (ORD), electronic circular dichroism (ECD) and vibrational circular dichroism (VCD) studies (see the ESI $\dagger$ ). The $[\alpha]_{\mathrm{D}}$ of the natural sample of 1 extracted from the gorgonian Isis hippuris was measured at $[\alpha]_{\mathrm{D}}^{25}=-60\left(c=0.1, \mathrm{CHCl}_{3}\right),{ }^{22}$ while the synthetic sample of $(1 R)-\mathbf{1}$ prepared by Dumas and co-workers showed $[\alpha]_{\mathrm{D}}^{19}=+53.4\left(c=0.1, \mathrm{CHCl}_{3}\right){ }^{5}$ On that basis, the absolute configuration of naturally occurring 1 was assigned as $(1 S)$. The measurement of the optical rotation of our synthetic samples of $(1 R)-1$ (er $>199: 1)$ afforded the following values: $[\alpha]_{\mathrm{D}}^{25}=+20$ $\left(c=0.1, \mathrm{CHCl}_{3}\right),[\alpha]_{\mathrm{D}}^{15}=+20\left(c=0.1, \mathrm{CHCl}_{3}\right)$, and $[\alpha]_{\mathrm{D}}^{25}=+11$ $(c=0.1$, EtOH $){ }^{23}$ Additionally, Stephens and co-workers predicted $[\alpha]_{\mathrm{D}}=-20.6$ (gas phase) for $(1 R)-\mathbf{1}$ by DFT calculations. ${ }^{4} \mathrm{~A}$ puzzling situation! Although we have no sound explanation for these discrepancies in the $[\alpha]_{\mathrm{D}}$ values, ${ }^{24}$ some clues came from the comparison of the ORD of our synthetic $(1 R)-\mathbf{1}$ with the predicted ORD (DFT) for (1R)-1, as well as with the experimental and theoretical ORDs of (1R)-quadrone (Fig. 2). On the basis of similar shapes of ORDs, and in line with Stephens and co-workers' intuition on the occurrence of a single absolute stereogenicity in quadranes biosynthesis, the absolute configuration of naturally occurring $\mathbf{1}$ is likely to be $(1 R)$. However, a clear-cut answer to this question can only arise from additional chiroptical characterization of the naturally occurring material.

In summary, a remarkable divergence was identified in dual organocatalytic transformations combining a secondary amine and a NHC catalyst, the NHC operating as the reactivity switch. A practical enantioselective method for the synthesis of functionalized bicyclo[3.n.1] derivatives resulted. This original switchable bicatalytic transformation opens up avenues for the conceptualization of switchable multicatalytic transformations. The dual catalytic method described herein was initially elaborated to provide the first enantioselective route to the cytotoxic quadrane natural products, which allowed the total synthesis of $(1 R)$-suberosanone and the formal synthesis of $(1 R)$-suberosenone. This work provides all the necessary chiroptical information for the determination of the absolute 


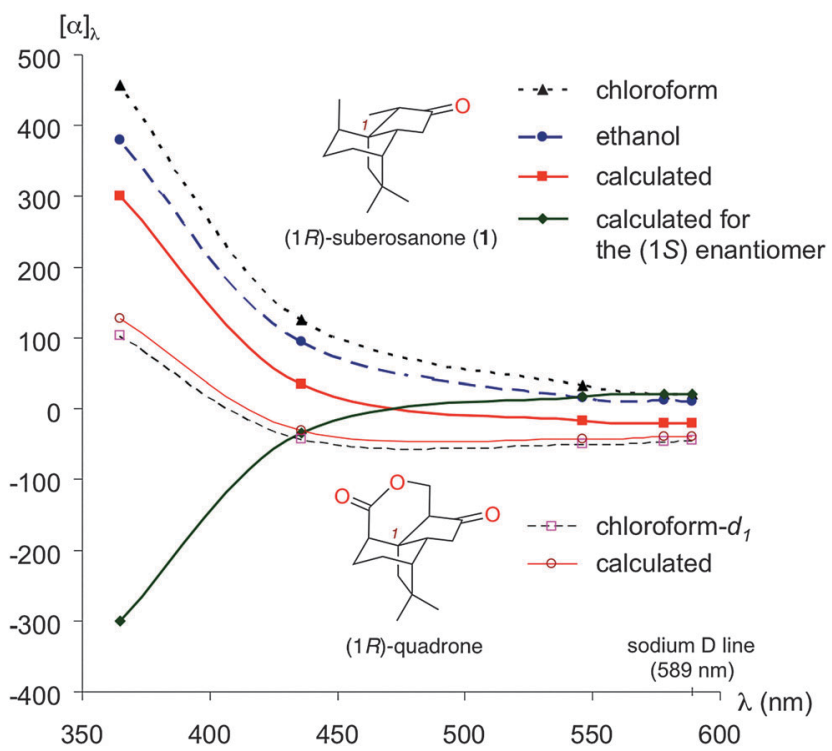

Fig. 2 Experimental and calculated ORDs of $(1 R)$-suberosanone (1) and $(1 R)$-quadrone. Data from ref. 4 and our own measurements.

configuration of naturally occurring suberosanone when more data are available.

Financial support from the China Scholarship Council (YR fellowship), the Ecole Normale Supérieure Cachan (MP fellowship), Aix-Marseille Université, Centrale Marseille, and the Centre National de la Recherche Scientifique (CNRS) is gratefully acknowledged. The CRCMM is acknowledged for support computing facilities.

\section{Notes and references}

1 Review: M. Presset, Y. Coquerel and J. Rodriguez, Eur. J. Org. Chem., 2010, 2247.

2 G. M. Cragg and D. J. Newman, Biochim. Biophys. Acta, Gen. Subj., 2013, 1830, 3670 and previous reviews from the same authors.

3 A couple reports on non-racemic diastereoselective total syntheses of quadranes, from the chiral pool and using a chiral auxiliary, respectively, have erroneously been entitled "Enantioselective total synthesis of...". See M. Torihata, T. Nakahata and S. Kuwahara, Org. Lett., 2007, 9, 2557, and ref. 5.

4 P. J. Stephens, D. M. McCann, F. J. Devlin and A. B. Smith, III, J. Nat. Prod., 2006, 69, 1055.

5 M. Kousara, A. Ferry, F. Le Bideau, K. L. Serré, I. Chataigner, E. Morvan, J. Dubois, M. Chéron and F. Dumas, Chem. Commun., 2015, 51, 3458.

6 Highlight: (a) M. Presset, Y. Coquerel and J. Rodriguez, ChemCatChem, 2012, 4, 172. Review: (b) M. Presset, Y. Coquerel and J. Rodriguez, Chem. Rev., 2013, 113, 525. Recent contributions: (c) M. Tsakos, M. R. J. Elsegood and C. G. Kokotos, Chem. Commun., 2013, 49, 2219; (d) A. Lefranc, L. Gunée, S. Goncalves-Contal and A. Alexakis, Synlett, 2014, 2947; (e) A. Lefranc, L. Gremaud and A. Alexakis, Org. Lett., 2014, 16, 5242; $(f)$ A. R. Burns, A. G. E. Madec, D. W. Low, I. D. Roya and H. W. Lam, Chem. Sci., 2015, 6, 3550.

7 Selected reviews on multicatalysis: $(a)$ L. M. Ambrosini and T. H. Lambert, ChemCatChem, 2010, 2, 1373; (b) S. Piovesana, D. M. Scarpino Schietroma and M. Bella, Angew. Chem., Int. Ed., 2011, 50, 6216; (c) R. C. Wende and P. R. Schreiner, Green Chem., 2012,
14, 1821; (d) A. E. Allen and D. W. C. MacMillan, Chem. Sci., 2012, 3, 633; (e) Z. Du and Z. Shao, Chem. Soc. Rev., 2013, 42, 1337; $(f)$ G. Jürjens, A. Kirschning and D. A. Candito, Nat. Prod. Rep., 2015, 32, 723.

8 Selected reviews: (a) K. L. Jensen, G. Dickmeiss, H. Jiang, L. Albrecht and K. A. Jørgensen, Acc. Chem. Res., 2012, 45, 248; (b) S. Meninno and A. Lattanzi, Chem. Commun., 2013, 49, 3821.

9 Y. Coquerel, M.-H. Filippini, D. Bensa and J. Rodriguez, Chem. - Eur. J., 2008, 14, 3078.

10 (a) S. P. Lathrop and T. Rovis, J. Am. Chem. Soc., 2009, 131, 13628. With $\beta$-ketosulfones: $(b)$ D. Enders, A. Grossmann, H. Huang and G. Raabe, Eur. J. Org. Chem., 2011, 4298.

11 (a) T. Boddaert, Y. Coquerel and J. Rodriguez, Chem. - Eur. J., 2011, 17, 2266. For the reversibility issue, see also: (b) E. M. Phillips, M. Riedrich and K. A. Scheidt, J. Am. Chem. Soc., 2010, 132, 13179. For other applications from our laboratory, see: $(c)$ M. Hans, L. Delaude, J. Rodriguez and Y. Coquerel, J. Org. Chem., 2014, 79, 2758; (d) F. Perez, Y. Ren, T. Boddaert, J. Rodriguez and Y. Coquerel, J. Org. Chem., 2015, 80, 1092; (e) F. Nawaz, M. Zaghouani, D. Bonne, O. Chuzel, J. Rodriguez and Y. Coquerel, Eur. J. Org. Chem., 2013, 8253. See also: J. Chen and Y. Huang, Nat. Commun., 2014, 5, 3437.

12 Hindered NHCs such as II react reversibly with aldehydes to produce shielded Breslow intermediates of reduced nucleophilicity, limiting their applications in the benzoin reaction. For a discussion, see: C. Burstein, S. Tschan, X. Xie and F. Glorius, Synthesis, 2006, 2418.

13 G. Lelais and D. W. C. MacMillan, Aldrichimica Acta, 2006, 39, 79. 14 Review: J. Gu, W. Du and Y.-C. Chen, Synthesis, 2015, 3451.

15 The triazolylidene catalyst employed in ref. 10 is $c a .10^{6}$ times less basic than the NHC catalyst II. (a) E. M. Higgins, J. A. Sherwood, A. G. Lindsay, J. Armstrong, R. S. Massey, R. W. Alder and A. C. O'Donoghue, Chem. Commun., 2011, 47, 1559; (b) R. S. Massey, C. J. Collett, A. G. Lindsay, A. D. Smith and A. C. O'Donoghue, J. Am. Chem. Soc., 2012, 134, 20421.

16 For switchable monocatalytic transformations with NHCs, see: (a) C. Guo, B. Sahoo, C. G. Daniliuc and F. Glorius, J. Am. Chem. Soc., 2014, 136, 17402; (b) C. Guo, M. Fleige, D. Janssen-Müller, C. G. Daniliuc and F. Glorius, Nat. Chem., 2015, 7, 842.

17 A control experiment using sodium acetate $(20 \mathrm{~mol} \%)$ as the Brønsted base left, as expected, the Michael adduct intermediate 3 unchanged after prolonged reaction time.

18 This diastereomeric enrichment is regrettably not possible with the $t$-Bu ester derivatives and the products incorporating a gem-dimethyl group.

19 The scale up study was realized before the conditions in Table 1, entries 8 and 9 were identified.

20 CCDC 1449766 contains the supplementary crystallographic data (CIF) for compound $\mathbf{8 a}$.

21 For reviews: (a) W. Kirmse, Eur. J. Org. Chem., 2002, 2193; (b) Y. Coquerel and J. Rodriguez, in Molecular Rearrangements in Organic Synthesis, ed. C. Rojas, John Wiley \& Sons, Hoboken, NJ, 2015, ch. 3, pp. 59-84.

22 Isolation and characterization: J.-H. Sheu, K.-C. Hung, G.-H. Wang and C.-Y. Duh, J. Nat. Prod., 2000, 63, 1603.

23 Mean values of 5 or more independent measurements on different synthetic samples performed by different operators.

24 We can remember that, as early as 1960 , in the introduction of his pioneer book on the subject, Carl Djerassi wrote: "The chief message of this book can actually be constructed as a complaint against this unfortunate temporary victory of monochromatic polarimetry over rotatory dispersion." And later on: "... rotations in the ultraviolet region are (for colorless compounds) invariably greater than for the conventional sodium D line. Comparisons of compounds with small $[\alpha]_{D}$ are therefore better carried out at a lower wavelength, which can be selected from the dispersion curve." C. Djerassi, in Optical Rotatory Dispersion, McGraw-Hill series in Advanced Chemistry, ed. W. C. Fernelius, L. P. Hammett, D. N. Hume, J. A. Pole, J. D. Roberts and H. H. Williams, McGraw-Hill Book Company, New York, 1960. 